\title{
Importance of Smart Metering in Diverse Fields of Smart Cities
}

\author{
Kiran Ahuja ${ }^{1}$ and Arun Khosla ${ }^{2}$ \\ ${ }^{1}$ Research scholar, ${ }^{2}$ Associate Professor \\ Department of Electronics and Communication Engineering \\ National Institute of Technology, Jalandhar, India \\ 1askahuja2002@gmail.com, ${ }^{2}$ khoslaak@nitj.ac.in
}

\begin{abstract}
The system infrastructure of modern electric power distribution is integrated with information and communication technologies (ICTs) in smart cities. By employing wireless sensor networks, both utilities and consumers are capable to convey, observe, forecast, and manage energy usage effectively and efficiently. In this paper, smart meters (SMs) deployment in diverse applications (such as water system, transport system, intelligent home/building's demand response system, zero energy buildings, industry automation, renewable energy system, street lighting system, smart HVAC systems, carbon management system, utilization of SMs in production of gas) have been conferred to measure precise energy usage and collect data to improve the overall system, while maintaining green environment as per the emergent need of the day. However, with deployment of SMs by employing wireless sensor networks have been acquainted with new security challenges, mainly related to confidentiality, connectivity, and protection management. These may cause unexpected expenditure and adversity to both utilities and consumers. The various deployment issues faced by utilities and consumers are identified for prosperous solutions. Emerging smart metering solutions are conversed to facilitate number of utilities and consumers for tracking of their energy usage, which will help better energy conservation in future.
\end{abstract}

Keywords: Smart meter, Smart grid, Smart cities, IoT, ICT, AMR

\section{Introduction}

Two third of the world's people will be living in cities by 2045 [1]. However, the rapidly increasing urban populace will continually raise load on infrastructure, transport, healthcare, housing and employment. It's high time to convert cities into more livable, workable, manageable Smart Cities (SCs). SCs are supposed to equip with high speed internet connectivity, smart transport networks, smarter energy system etc. Appropriate energy system is the basic need of every city. If electricity is not available for a momentary period of time, then all the functions will ultimately cease. The huge hurdle in establishment SCs in near future is need of smart energy system. The new initiatives are required to gear up power and manage the SCs as per the requirements. A smart energy system should smartly utilize the electricity by recording the live data of various residential, industrial and commercial spaces. Smart Grids (SGs) are integral part of SCs as shown in Figure 1. SCs are dependent upon SGs to ensure flexible release of energy to facilitate users for their routine functions, conservation, and for coordination between urban officials \&operators. SGs upgrade power systems through establishment of micro grids, automation, self-healing designs, and remote monitoring [3]. These inform the consumers about their energy consumption, costs and alternative options, so that

Received (December 21, 2017), Review Result (March 2, 2018), Accepted (March 5, 2018) 
they can manage electricity usage. SGs assist compilation and transmission of electricity associated data all over the city, without hurdles and labor [2]. The basic need of every living entity in SCs is to have exceptional control over their electricity usage, so that they can reduce their electricity bills smartly and efficiently. This will help in reduction of uncontrolled electricity usage and release huge pressure on the resources of electricity. These also offer secure, safe and consistent fusion of distributed and renewable energy resources. All these additions to an energy system make it more sustainable, reliable and resilient. Thus, a smart grid is a heart of smart energy system in smart cities.

SGs upgrade the energy system and SGs are upgraded by inclusion of emerging smart meters. The analog meters are still in usage and haven't altered since 1800s. These can't record data and unable to link with grids [4]. Whereas, SMs are able to provide accurate bills and make feasible variable tariffs depend upon live usage. These will help in maintaining energy on demand. Formerly, once SMs are installed, then residents will be capable to save money by shifting to off peak times. These will increase the scope of cost cuttings. A few countries around the world have already implemented SMs technology to bring innovation and upgraded services. These can also play a significant role in making cities greener, as renewables effectively and more easily incorporated into the energy blend. Improved energy management in cities will be able to initiate other smarter and greener criterion in future, such as electric vehicles. These can further decrease air pollution and carbon emissions. Electric vehicles cannot sustain without SM's deployment, as SMs help in maintaining the demands on the grid, especially when vehicles are being charged at night.

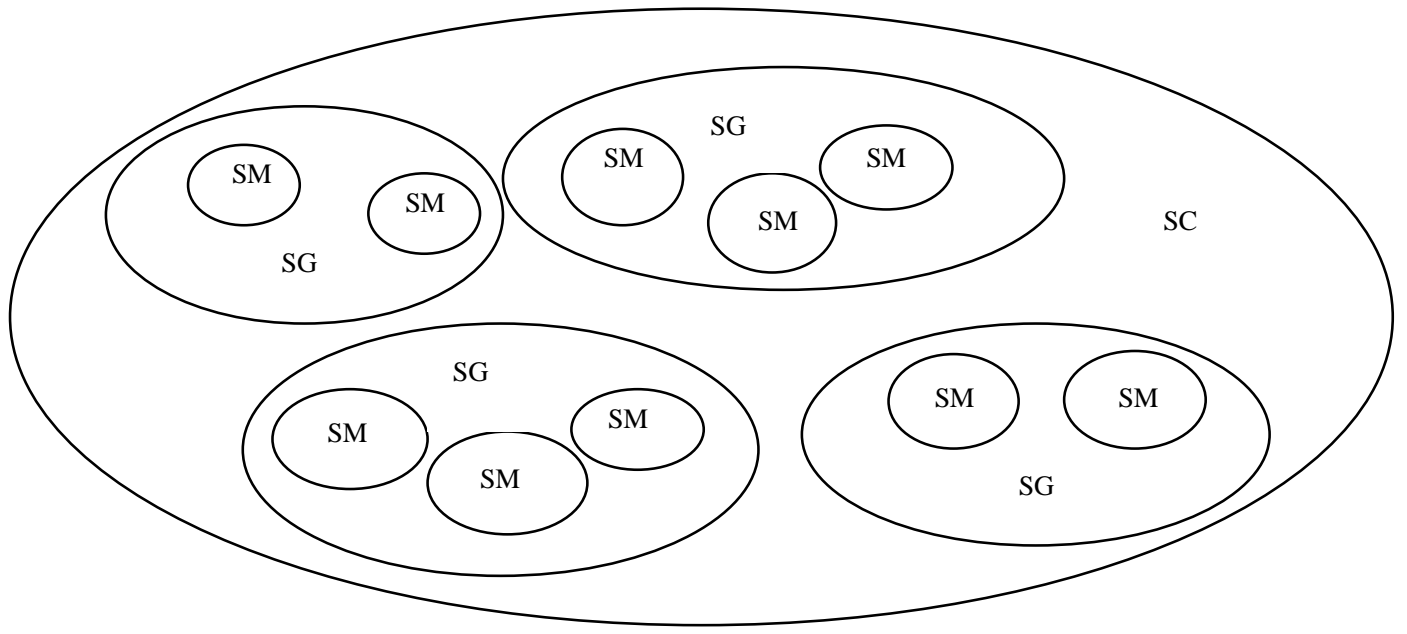

Figure 1. Integration of Smart Meters (SMs) With Smart Grids (SGs) and Smart Cities (SCs)

The backbone of a smart energy system in SCs is the smart energy grids consist of SMs. In this paper, deployment of SMs in various fields of SCs has been discussed in detail. The comprehensive review of deployment of SMs will clear its dreadful requirement in coming future. The most prominent challenges in smart meters' deployment are discussed in detail. Number of smart metering solution providers, those help in maintenance and sustenance for consumers and utilities are described. The paper is organized as follows. Section 2 presented the literature survey about SGs consist of SMs in various fields of SCs. In Section 3, need of smart metering and SMs in various fields of SCs are discussed in detail. Section 4 identifies smart metering deployment issues. In Section 5, emerging solutions related to smart metering are discussed. Finally, conclusions are drawn in Section 6. 


\section{Literature Survey}

Numerous technologies have been prevailed for smart metering and geared up to take steps towards implementation. Electrical distribution systems are presently equipped with high levels of communication, automation and information technologies. Electrical distribution systems are ready to facilitate number of utilities to enhance reliability. It's a time to drive more intellect into substations and faster decision-making field equipment for fault location, isolation and restoration, voltage \&reactive power management and feeder reconfiguration. On the same pace, a growing perforation of renewable generation created an emergent need of management of adaptive safety equipment and extension of associated substation designs. In particular, defined standards for technologies implementation, integration with information and operations are mandatory for efficient designing.

Domestic SMs determine power usage in real time at high accuracy. Researchers in [5] stated that the extensive deployment will have serious privacy implications, as these can unintentionally disclose thorough information about domestic activities. They claimed that without knowledge of domestic activities, it is feasible to extract consumption patterns from smart meters by employing statistical techniques. The patterns revealed a range of routine information, which indirectly ceased the security. There is need to design and implement smart meters, which can allow utility to achieve their goals without any compromise with the privacy of consumers. Whereas in [6], authors focused on SM's time shifting feature to take load off peak hours. It ultimately reduced cost by working during off-peak hours, which directly improved the reliability of the network.

Authors in [7], addressed challenges exist in the smart grid technologies and discussed the intelligence systems, which could help to resolve these. In [8], authors are mainly focused on the challenges in implementation of SGs in India. In most of the developed countries, utilities made considerable achievements in terms of efficiency, reliability, and productivity by employing smart grid technology. In India, utilities are lagging behind as compared to developed countries. Here, struggle is to provide basic required energy at a reason able rate. SGs and SMs must ensure consumers, utilities, communities about reduction of cost and better consumer services. An application analysis and classification of significant privacy and cyber security issues are presented in turn to make a trustworthy wireless sensor network for smart grid in [9]. A cohesive structure for challenges and applications of wireless sensor network in smart grid was developed.

Researchers in [10], stated that network infrastructures play an important role to make possible sustainable, innovative and user-friendly services such as energy efficiency, low carbon footprint systems etc. For citizens, smart metering and SGs enable services viz. building automation, mobility, city lighting and interoperability between cutting edge technologies. The SGs will make power sector more efficient and sustainable affirmed by researchers in [11]. There is a need to manage demand of electricity while maintaining resilience, reliability, stability and the best quality of service with reduction in electricity bill. By deploying SMs, consumer's participation also enabled energy management. In [12], authorities talked about the deployment and analysis of load management of domestic consumers by implementing SMs and SGs. The investigation of data outcomes of SMs installed in the utility is being done. SMs are equipped with two-way communication, polling period, data evaluation, and deposition features. These can display consumption data to consumers, support variable tariff and micro utilization/production. They also highlighted the practical issues related to the deployment of SGs in distributed energy system. 
Authors in [13], explained that SMs read and recorded electric energy consumption after particular time of interval and communicated data to the utility for observation and billing purpose. The data is more accurate and reliable provided by SMs as compared to manual reading or recording. For effective storage and efficient delivery of data, smart or intelligent batteries need to be prepared from lithium-ion or fuel cells for longer life. Without integration mechanism, the Energy Management System (EMS) will lose the charm to upgrade efficiency and cost cutting. The lack of coordination in existing EMS has been addressed in [14] by developed an integrated, advanced, management system. The system was designed for consumers to take decision about them as well as for public infrastructures.

As discussed previously, smart cities need to be energy proficient and technology driven. With rise in urbanization, the efficient energy utilization is one of the main tasks of smart cities. There is need to focus on smart energy meters' deployment for low energy usage, renewable \& green energy and small carbon emissions footprints. In the following section, significance of SM's deployment in various fields of smart cities is discussed in detail.

\section{Need of Smart Metering in Smart Cities}

Smart metering encourages smart energy systems with more alternatives and incentives by involving residential, communities, industrial and commercial segments of smart cities in energy conservation, competence and demand response. Home and building automation systems are important elements of this movement. These will increase in gradual manner in future. Advanced smart metering systems will collect, evaluate and devise required information to predict, find out the load response and get better operational decision making in diverse fields of smart cities by data management and data analytics. The main fields of smart cities where SMs/SGs deployed for improvement are shown in Figure 2. and discussed as follows:

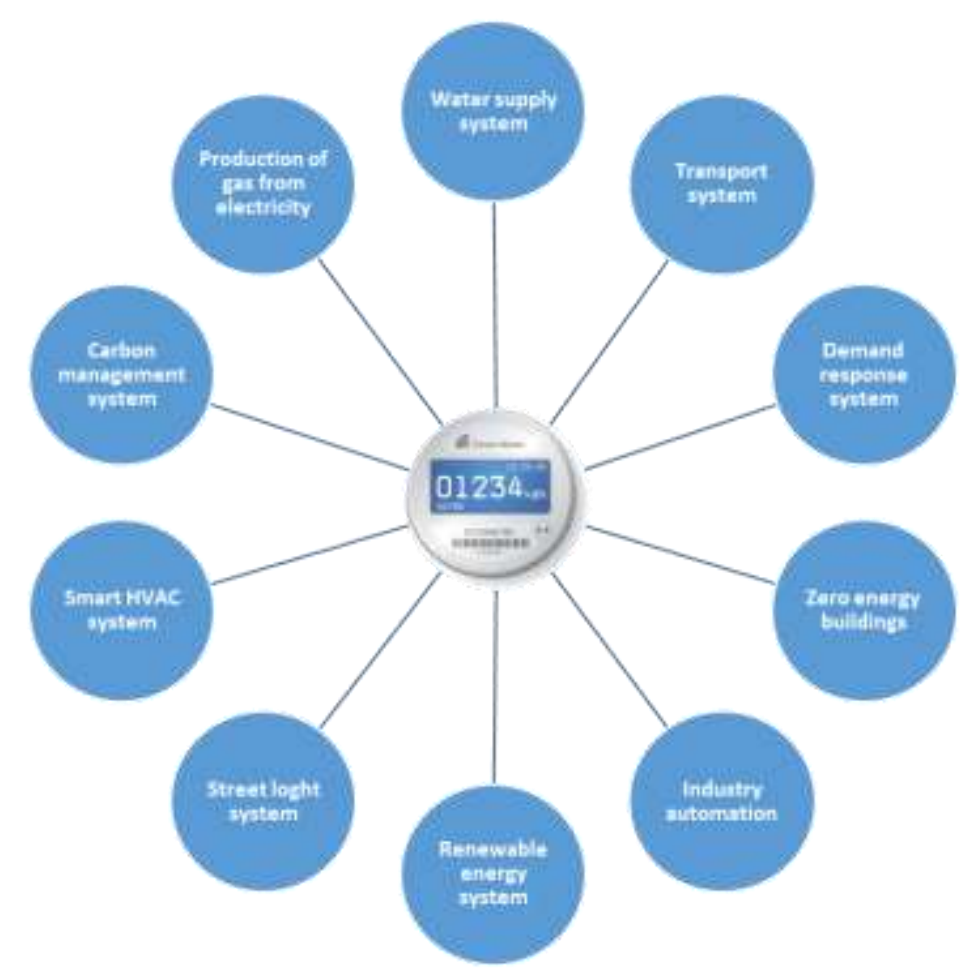

Figure 2. Represents Various Applications of Smart Metering in Smart Cities 
Water Supply System: Largest consumers of energy in smart cities are water utilities for pumping process. By employing SMs, consumption of electricity can be observed. Water utilities take advantage of these observations by avoiding electricity consumption in peak hours to save cost, when energy has high cost. This is only possible by coordination between the electric utility and water utility by preferring work in non-peak hours. The smart energy system will help the water utility to decrease its energy usage and eventually its bill too as shown in Figure 3. It will avoid problems and allow maintaining uninterrupted power as well as water supply for critical areas such as hospitals by two communication system [15].

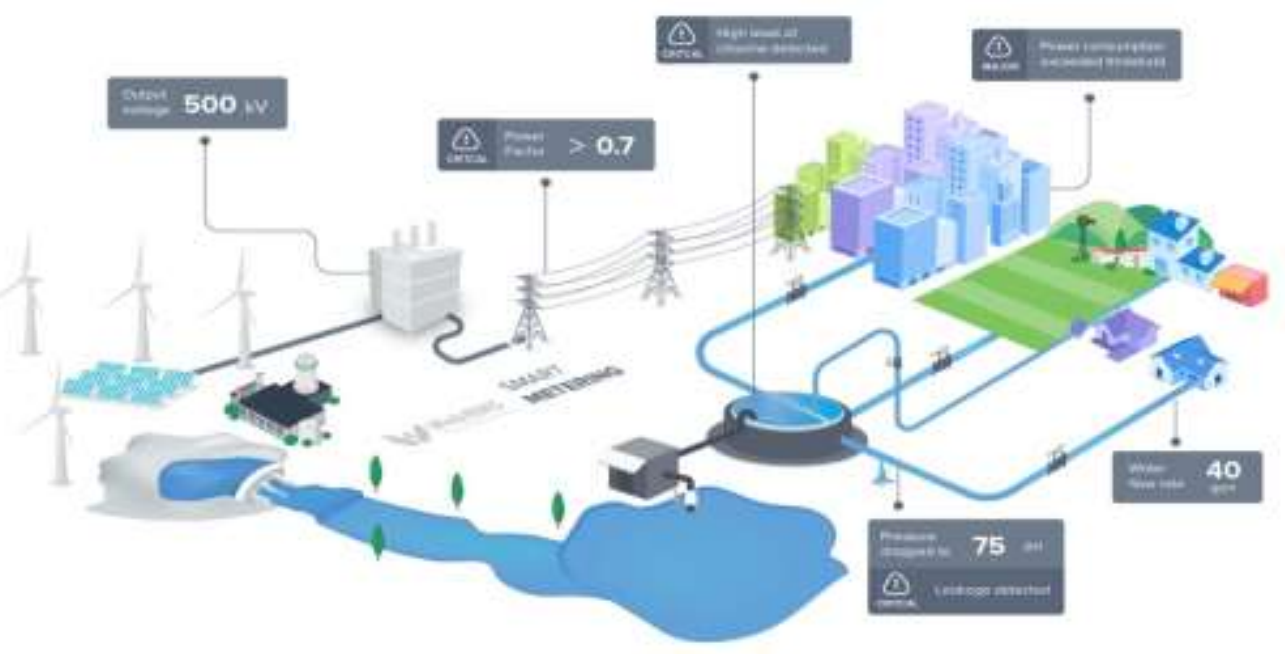

\section{Figure 3. Represents Smart Energy Meter Deployment in Water Supply System [16]}

Transport system: The challenges like global warming, diminishing availability of fossil fuel us to think towards electrification of transportation system. It can be considered as one of the solution. The evolution of plug in electric vehicles for transportation provides opportunities as well as challenges to process and planning department of power system. If electric vehicles are considered as a routine load without providing flexibility and control over the charging then it can create problems at diverse levels, such as threaten the secure function of installed resources. The charging of electric vehicles can be managed by measuring load at different intervals by employing smart meters. To avoid overload on power system the charging load of electric vehicles can be shifted to low load hours by utilize SMs' status carefully. Electric vehicles work like distributed storage system, which support supplementary services such as peak power saving, frequency regulation and integration with fluctuating renewable systems as shown in Figure 4. It fits well in the paradigm of SGs too. An advanced utilization of communication technologies and metering system raised controllability and load flexibility [17]. SMs are directly or indirectly control the charging of electric vehicles and work as an interface with other entities such as energy service providers. SMs communicate considerable amount of information between vehicles and control entities. On another way, electric trains are accelerated by employing smart energy system components and reduce power consumption, while maintaining routine schedules.

Intelligent home/buildings/ demand response system: Electric utilities are developing new technologies and energy services by deploying smart meters. They make consumers proficient to observe their energy usage, communication with utilities, and control their bills by installing mobile applications. Several utilities are 
encouraging consumer's involvement by incorporating demand response system via advanced metering systems. The public and building owners play an important part in demand response criterion at the same note. The smart city consists of such smart buildings in which all data points combined and analysis of the smart grid can be done on the basis of demand response criterion. The most critical responsibility of a smart city is to maintain the logistics information seamlessly through coordination with the public [19]. The SGs with the help of SMs would drop load in an expected and more controllable manner so that smart city's critical infrastructure (such as fire, police, hospitals) and tasks are maintained by micro grids as shown in Figure 5.

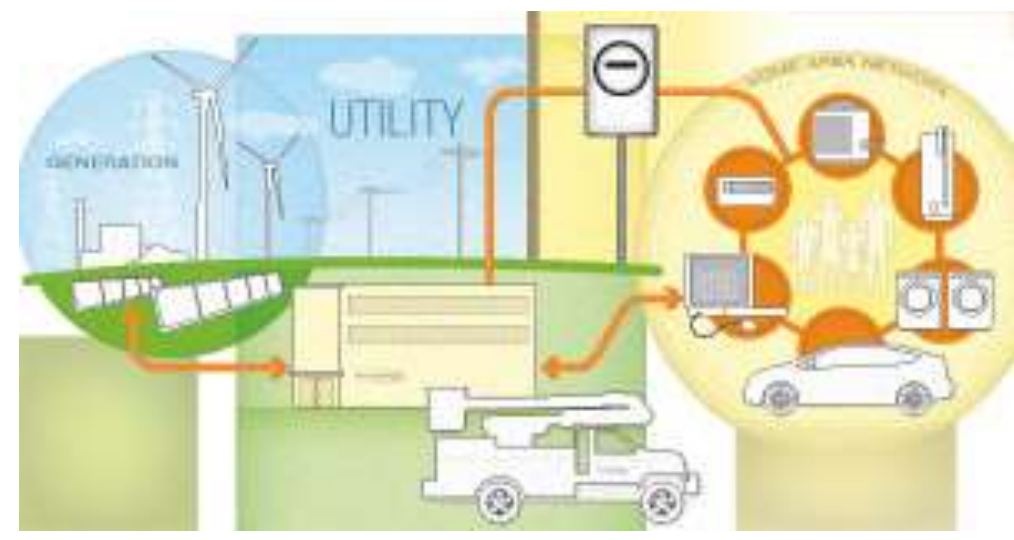

Figure 4. Shows Importance of Smart Metering in Transportation [18]

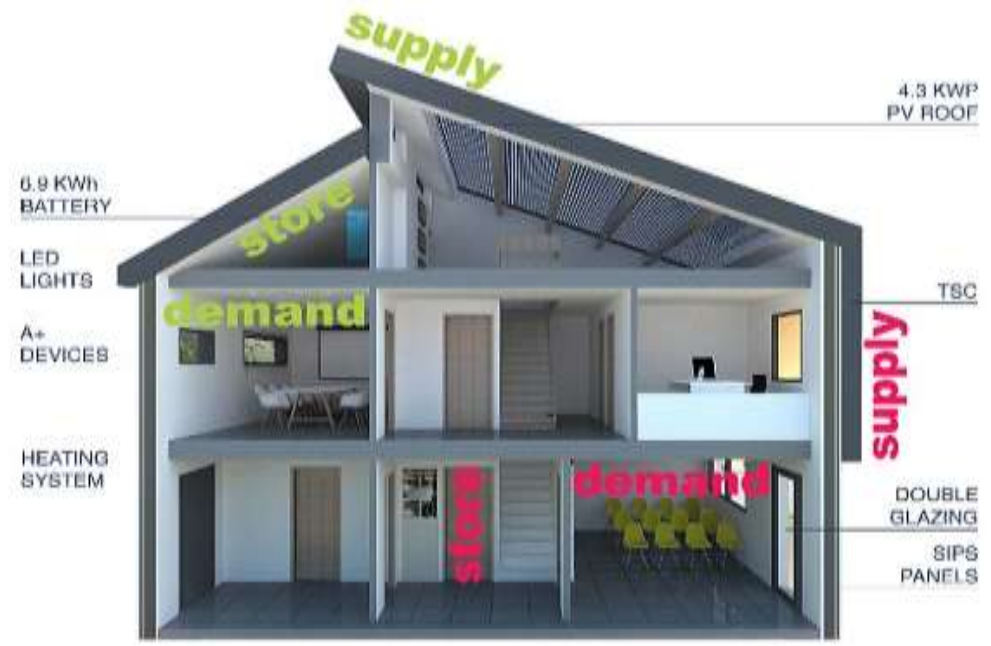

\section{Figure 5. Shows Demand and Response Supply Dependent upon Smart Energy Meter's Readings [21]}

Zero energy buildings: A building with approximately net energy usage zero is defined as zero energy building. The sum of energy produced by renewables onsite is approximately equal to the sum of energy used up in the building within a year in case of zero energy building. A smart meter system is a very basic requirement for these buildings to handle and control the energy flows. As smart metering observes, manages, envisions and accumulates the energy produced and consumed in a building, with provisioning of information to consumers. So, it is an innovative approach to employ smart metering system in zero energy buildings. The system performance is analyzed by positioning of smart meters, gathering data, load monitoring and overall grading. Smart meters are deployed for acquisition and communication of energy data to a central system for supervision as shown in 
Figure 6. In [20], researchers proposed a classification of smart metering and defined criteria for overall grade evaluation of an individual smart meter.

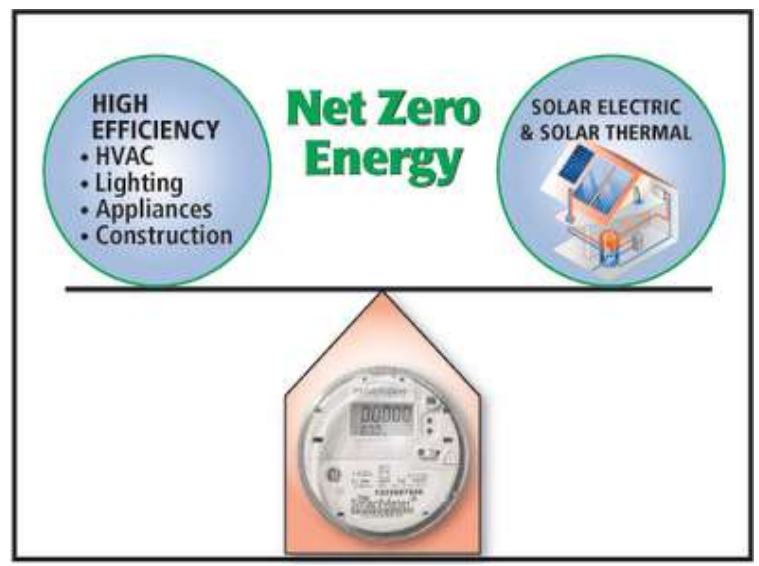

\section{Figure 6. Demonstrates Zero Energy Building's Balancing Check by Smart Meter [22]}

Industry Automation: Trends in the industry have demonstrated that energy utility companies are moving towards smart meters, therefore Automatic Meter Reading (AMR) solution are pooped up instead of manual or touch read devices. AMR also ensures a stable smart-grid. AMR with its predictive analysis helps in reducing unexpected load on grid, while making system more resilient to failures. Restorative automation brings back power quickly to areas, where alternating routes are available in case of failures. Local/Divisional generation can be utilized to maintain urgent requirements. The residential, industry, commercial community would react automatically, to decrease their energy requirements for reduction of load restoration. Through smart meters, logistics data can be collected timely and provided to community by available communication media as shown in Figure 7. Storage, safety and efficiency will be highly improved via accessibility of precise logistical data [23].

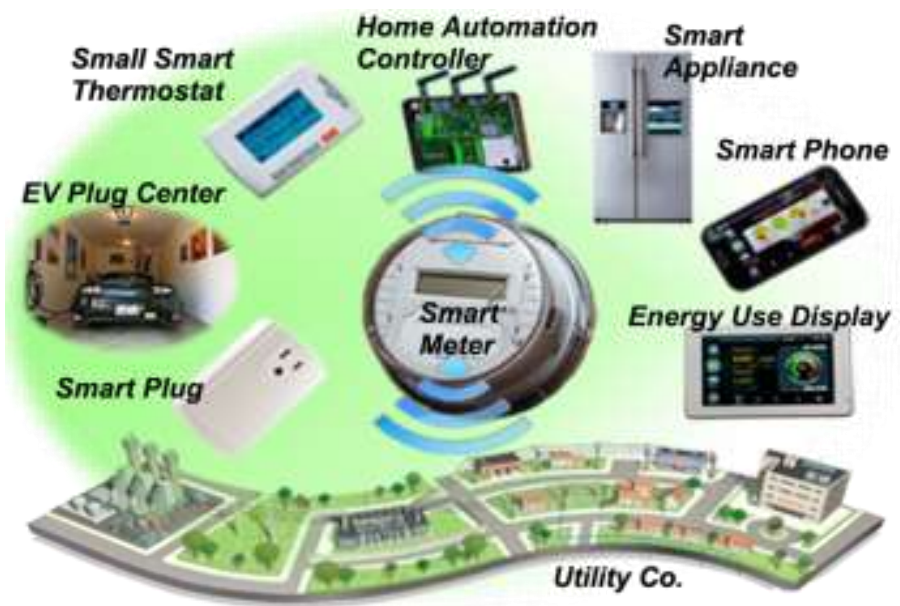

Figure 7. Illustrates Industrial Automation Revolving Around Smart Meters [24]

Renewable energy system: A range of emerging smart grid technologies is available to enhance grid performance and penetrate higher levels of renewable energy. SGs are cost effective, while establishing new or improving the old ones. By 
inclusion of smart meters, the cost effectiveness of smart grids will improve [25]. SMs can compute and track the production of a rooftop photovoltaic (PV) system/ renewable energy system and transmit information back to utility by controlling grid as shown in Figure 8.

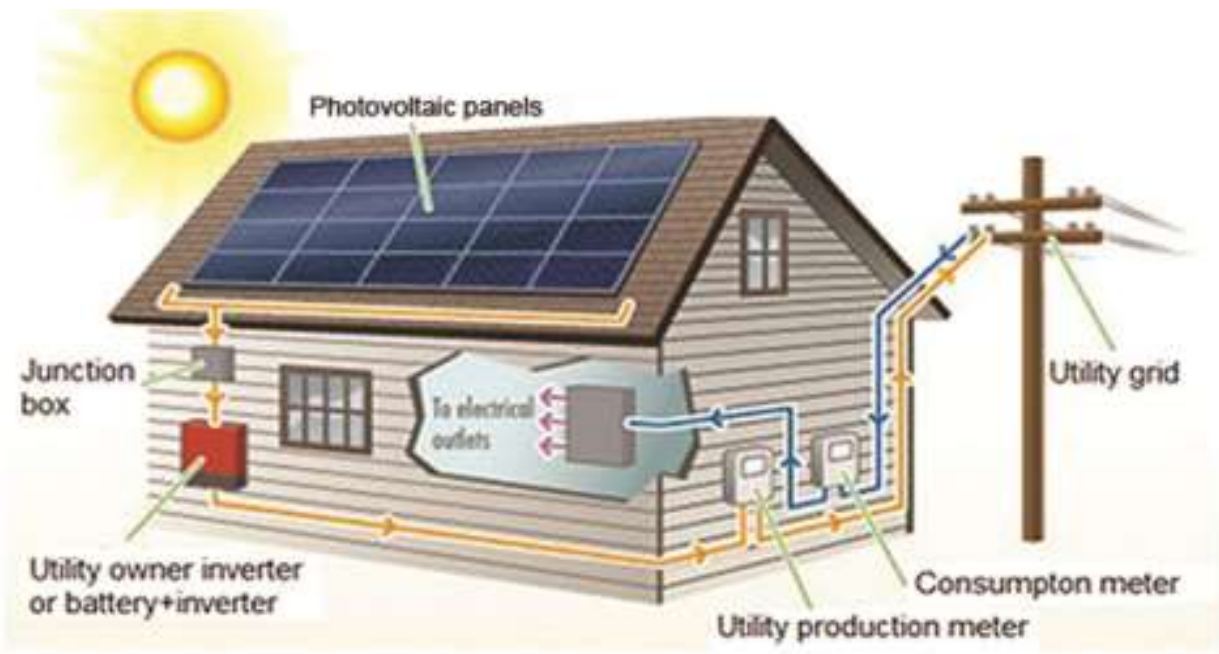

\section{Figure 8. Represents Utilization of Smart Energy Meters in Renewable Energy System [26]}

Street lighting system: One of the problems is to link energy usage billing of street lights. It is an unmetered/unnoticeable/unpaid load. The authorities of municipalities have to give vague and based on bills (such as approximate consumption per hour) ADDAX Light [27] provided a centralized management solution for a street lighting network. They offered smart metering and energy quality monitoring along with supervision of device installed in system. ADDAX Light enables fast and consistent data exchange. It controls configuration and operation of lighting network. It manages individual street lamp by including smart meter and modem. It controls more than one lamp simultaneously and performs step less dimming, which extends the lifespan of lamp. Precise metering of each lamp's consumption will avoid an approximation based billing. Balance metering is possible by installing SMs and these will detect frauds or leakage tries. When a particular lamp becomes inoperative, the light control unit makes an alert alarm and forwards it to main control system as shown in Figure 9. This attribute faster localizes the position of defective lamp and in time send a complaint to service team for fixation of the malfunctioning.

Smart HVAC systems: The prospect of smart HVAC (Heating, Ventilation and Air Conditioning) systems is to economize the natural resources especially fossil fuels, as indubitably it will arise in future. There is need to have regulations for smarter cooling and heating in latest buildings, so that these will become more energy competent. Smart HVAC systems will turn into an essential investment in near future, if consumers and utilities are decided to alleviate their side effects on the environment and save money as shown in Figure 10. Sensors which can commune with smart meters, smart phones and apps are available on the websites and make possible lowering down utility bills or keep them in manageable range in HVACs systems. According to the industry/market [29], smarter HVAC systems can instantaneously raise energy efficiency by 20 percent on installation. These systems will target domestic consumers and industry managers' real-time values, which raise system's efficiency by 30 to 40 percent. With SMs deployment, consumers and 
business persons are often socked with high bills during peak load hours. A smart HVAC system employment will provide smart finances too.

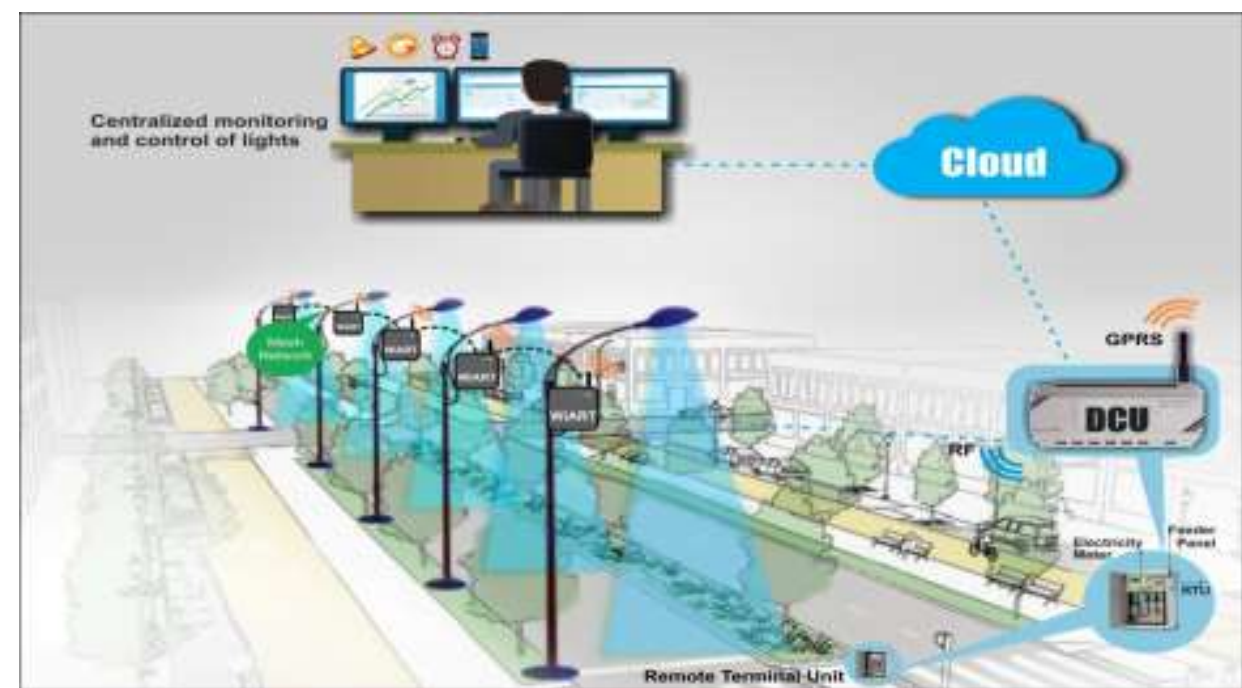

Figure 9. Described Deployment of Smart Meters to Calculate Street Lights' Energy Consumption Bill [28]

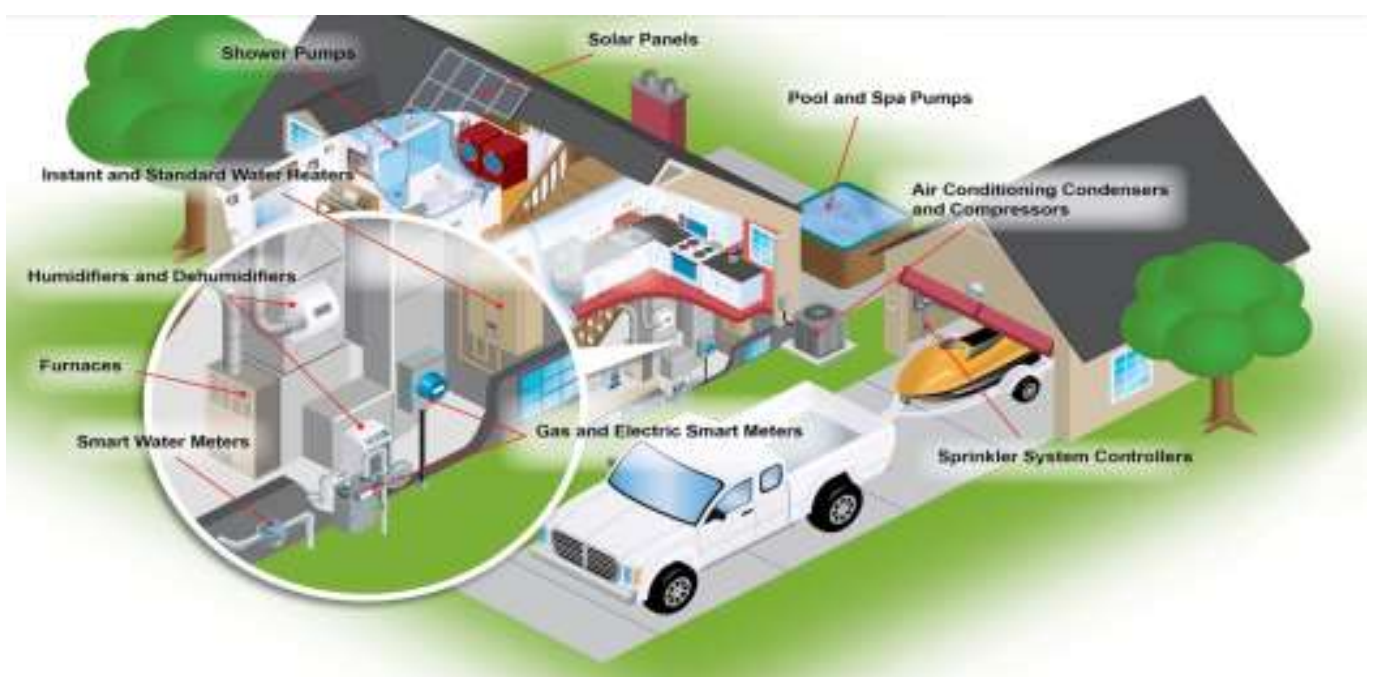

Figure 10. Demonstrates Smart Energy Meter's Usage in HVAC System [30]

Carbon management system: SMs come forward as a competent tool for carbon management. But 'smartness' doesn't mean to simply replacing old technologies with new for carbon reduction. The requirement is to change the rules of utility market, with an intention that demand and supply can contend on an equivalent basis. There is a need to incorporate the details of user's engagement with the system while planning. The main constraint here is to work on demand response [31]. The implementation of SMs and their related technologies vary in case of local or geographical conditions such as infrastructural, climatic, regulatory or social. Over the next decade, it is expected that smart metering will become the routine part of the world. By employing smart meters, peak demand and on whole reductions in consumption can be calculated, which directly help in carbon reductions from electricity production as shown in Figure 11. The solo emission reduction is lowering the release strength, due to this zero-carbon generated and efficient utilization of fossil fuel become via demand variation. It will indirectly reduce the 
production volume which will reduce emissions by two to three times. But little amount of carbon generation increased in blend [32].

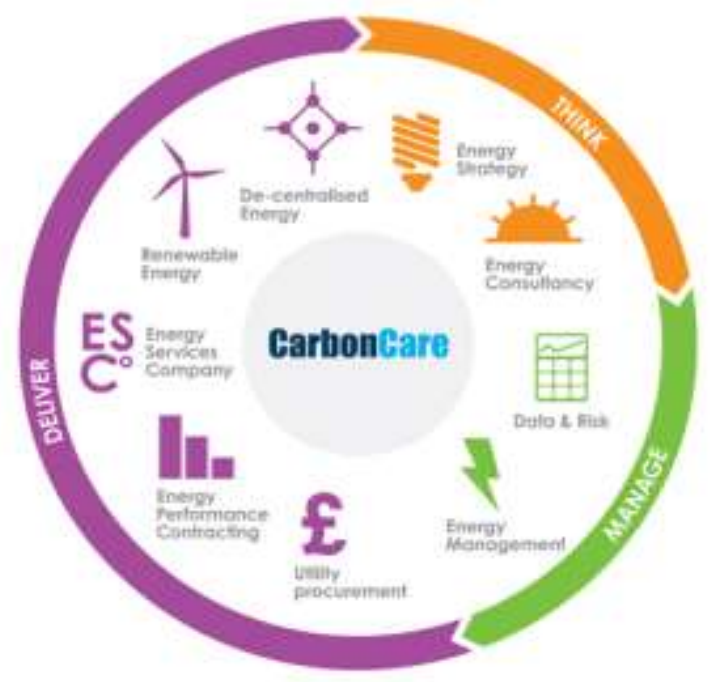

\section{Figure 11. Illustrates Carbon Emission Reduction by Deploying SMs in Various Fields [34]}

Utilization of smart meters in production of gas: Innovative techniques make possible to generate gas from electricity. When energy generated by renewable techniques exceeds than the requirement at that point artificial gas can be produced from surplus electricity. The availability of excess electricity is measured by employing smart energy meters as shown in Figure 12. Electricity is used for electrolysis process. Then by methanation process natural gas is produced. Gas can be transported, stored and used for a vehicle fuel or heating process. This technology is known as power to gas. There is need to link up smart energy and gas meters' systems intelligently and efficiently to minimize energy wastage [33].

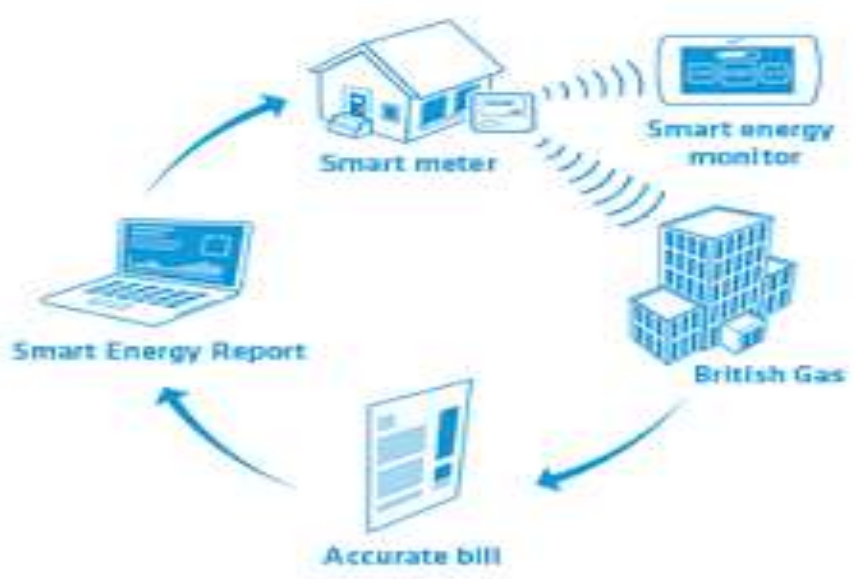

Figure 12. Demonstrates SMs Utility in Gas Production by Using Electricity [35]

For a city to be considered as smart, if its populace has every day's requirements experienced in the most competent and sustainable way. There is a need of synchronized management of resources (such as material, environmental or human) by urban authorities (public and private) in various divisions. However, as per above 
discussion, the management of various urban services is in a distributed manner across multiple stakeholders. As SMs deployment is to improve smart energy system's service proficiency in diverse fields such as water system, transport system, intelligent home/building's demand response system, zero energy buildings, industry automation, renewable energy system, street lighting system, smart HVAC systems, carbon management system, utilization of SMs in production of gas. Due to SMs deployment, it is possible to maintain and make sustainable smart and green energy system for upcoming smart cities.

\section{Deployment Issues of Smart Metering}

Energy companies/utilities/enterprises recognize potential business opportunities in deployment of smart energy meters with challenging issues, as described in Figure 13. Smart metering is a business changing plan. Here, a high level of information exchange and inter-system communication is required. Initially, consumers are in need of number of suppliers, so that they can switch/choose suppliers with ease as per their respective requirements. On the basis of providing accurate service to the consumers, the suppliers can compete with each other [36].

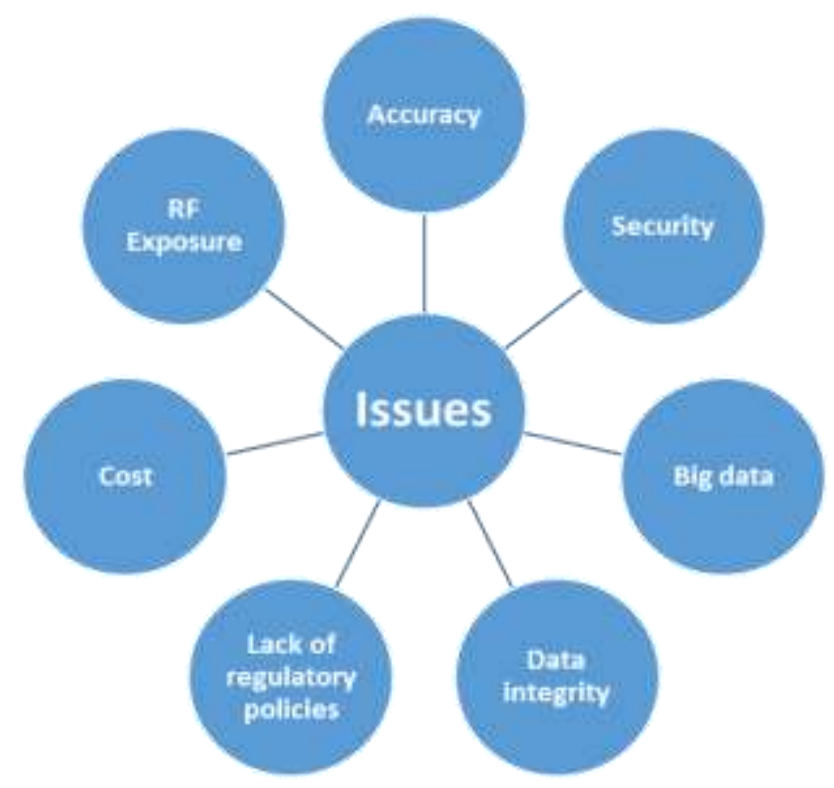

Figure 13. Represents Smart Energy Meters' Deployment Issues

Smart meters deployment should be fully awakened and satisfactorily adopted by consumers. The consumers' privacy is at risk due cyber-attacks. To ensure the consumer's privacy, a privacy check is required at utility's security end so that data can't be hacked. Data management and acquisition is still a critical issue for smart metering networks. The major challenge is to integrate various systems and manage progressively large volumes of data [37]. In this context, big data technologies suggest appropriate solutions for utilities, but which big data technology is to be employed, is a critical choice. Data integrity is an intense problem for consumers and operators. Energy companies should create a trust in consumers and they should compile the data as an asset for benefiting consumers with care and asset management. It is tough to establish a trustworthy data, because actions need to be taken in accordance with regulations arrangements and existing regulatory demands. Smart metering deployment also faces problem due to the lack of regulatory policies and strategies [38]. The next biggest challenge is to attract consumers and engage them in costly infrastructure projects as this infrastructure needs to last for years 
[39]. Rapid technological change is another tempting challenge and these fluctuations could change the whole market scenarios. One more challenge is to provide information to consumers about radio frequency (RF) emissions from the smart meters. The intensity of RF radiation can be calculated by smart meters' specifications, such as duration of reading, frequency of outputs, rate at which information transmit and receive from all sources etc. [40].

\section{Emerging Smart Metering Solutions}

The International Energy Agency [41] predicts the $37 \%$ hike of global energy demand by 2040. This will create a strain for utilities and energy suppliers. But utilities are trying to find solutions by employing Internet of Things (IoT). These make energy usage more efficient and effective, which will help in relieving some stress on energy demand. Smart meters have become the most popular IoT device for energy utilities and companies. The popularity will go on rise in the upcoming years. In Figure 14, the survey conducted by BI intelligence has been outlined, in which number of installed smart meters with respect of years has been given [42].

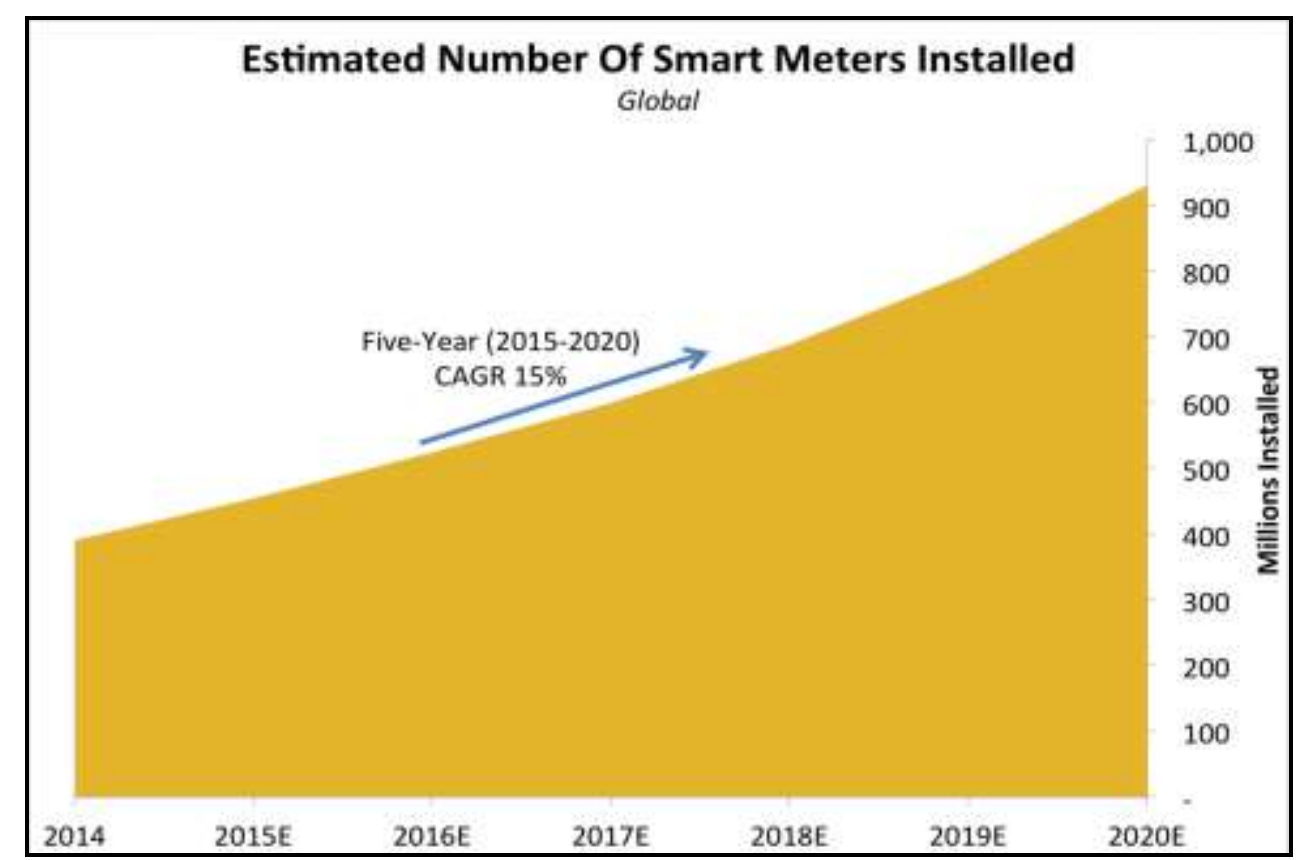

Figure 14. Represents Number of Smart Meters Installed with Respect to Years [42]

BI Intelligence estimated that installed smart meters' ratio will rise from 450 to 930 million in 2015-2020 tenure. This represents $15 \%$ annual growth rate and number of smart meters' installations will increase approximately 134 million by 2020. By using smart meters, BI intelligence predicts that the utilities can save up to 134 million by the end of 2035, as shown in Figure 15. 


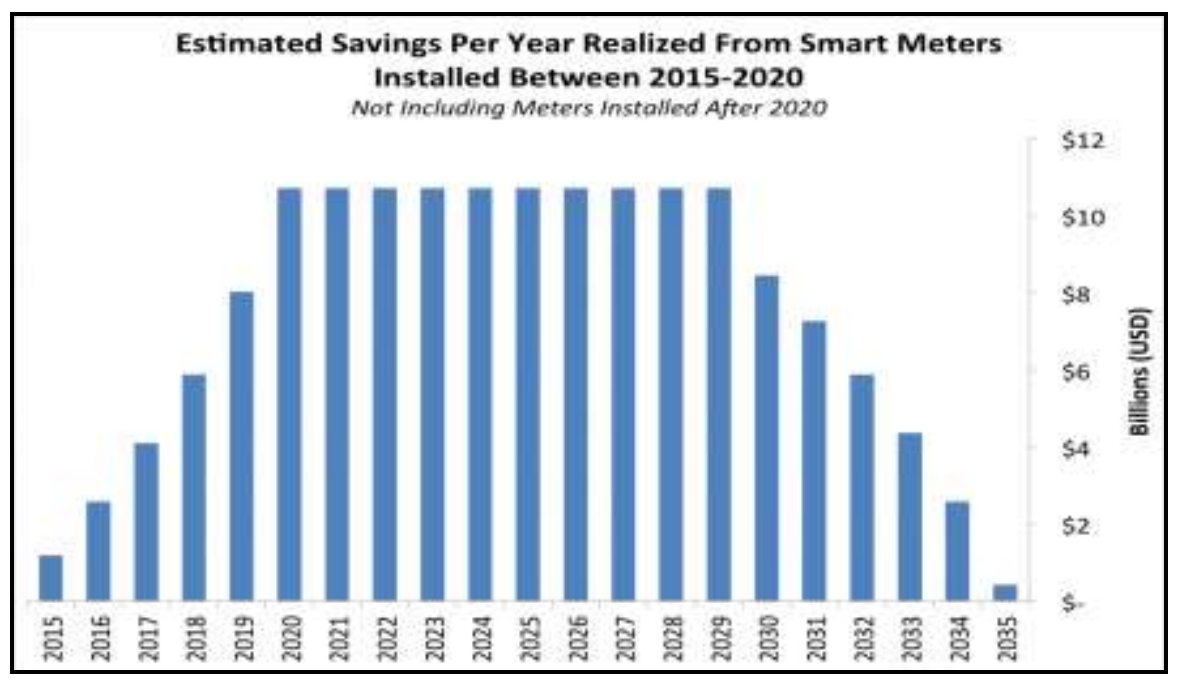

Figure 15. Represents Estimated Savings by Installing Smart Energy Meters [42]

Various emerging smart metering solutions are providing highly secure communications and playing an essential role in bringing energy saving initiatives for consumers', while providing the data to make better decisions. WebNMS engineered smart metering solutions for residential, commercial \& industrial applications are providing controlled consumption, enhanced productivity, better visibility, reduced operational costs and improved efficiency [43]. Landis+Gyr offers environmental friendly integrated smart metering solution that enable utilities and consumers for better usage of resources, having low operating costs [44]. Aclara's bring residential \& commercial smart metering solutions for better accuracy and providing better clarity about total power consumption by consumers [45]. Whereas, Arqiva is bestowing highly secure electricity smart metering communications and play an important role in energy saving \& better decision making [46]. Powel is another leading energy software solution provider in public sectors. Solutions have been developed to drive environmental friendly output, while maximizing available resources usage [47]. SilverLink's provide solutions for advanced metering in a multi-application environment. They ensure seamless, interoperable connectivity in smart grid network [48].

However, ZONOS ${ }^{\mathrm{TM}}$ AMM solutions provide management \& control of large and complex infrastructures of smart metering. They provide interfaces to existing systems and manage consumer data with their respective meter reads [49]. Mindteck solutions offer sustainable energy solutions for optimal energy consumption and facilitate distributed energy generation through smart grid technologies implementation [50]. Whereas, Secure solutions make available value added smart energy solutions for utilities. They offer comprehensive range of intelligent metering products and energy efficient devices [51]. Sierra Wireless solutions deal with machine-to-machine (M2M) technologies, cloud platforms, expert smart metering development assistance and many more [52]. CyLec provides retrofitting smart metering solution. They allow utilities to incorporate technology enhancement with existing installed meters by replacement [53] and Cyan's retrofit technology solution provides smart functionality to the existing static meters. Utilities can rapidly migrate from AMR, to an automated two-way AMIs for connecting the consumer and grids. In consequences, Kamstrup provides 
solution for intelligent metering by heavily investing in narrowband internet of things (NB-IoT) communication for existing electricity meters [54].

While, Aircel solution records electric energy consumption and provides twoway communication between the utility and the meter. Utility can take automatic meter readings by employing Aircel gateway device, which is connected to the Utility's digital meter. Aircel cellular connectivity is utilized to transmit meter readings on a regular basis [55]. Although, Cognizant solutions provide services to utilities for assessing benefits from smart technologies. They effectively manage their network assets to improve the efficiency in distribution operations and revenue cycle management [56]. winAMR offers solutions for utilities, which covers a range of metering devices (MR) and communication channels (AMI). Their solutions support various technologies like Power Line Carrier Communication (PLCC), Radio Frequency (RF) mesh, Global System for Mobile communication (GSM), General Packet Radio Service (GPRS), IPv6 over LowPower Wireless Personal Area Networks (6lowpan), etc. [57]. Huawei and their partners offer an end to end (E2E) solution, which covers the terminal, network, platform, and application layer. Huawei provides network communication, management \& control system, whereas partners provide application and terminals' software [58]. ADD GRUP is dedicated to develop powerful solutions for full control and management of smart metering infrastructure that help utilities to create a real time reliable platform for the coordination between its consumers and suppliers [59]. Whereas, Texas Instruments delivers three-phase smart energy metering solution for accurate power measurement and communication provisioning to e-metering. High voltage protection and ground isolation with accommodating data rates for emerging e-metering protocols are provided by Texas Instruments. They deal with 32-bit real-time microcontroller (MCU) with onboard memory process system for data [60]. The various smart metering solution available in market are enlisted in Figure 16.

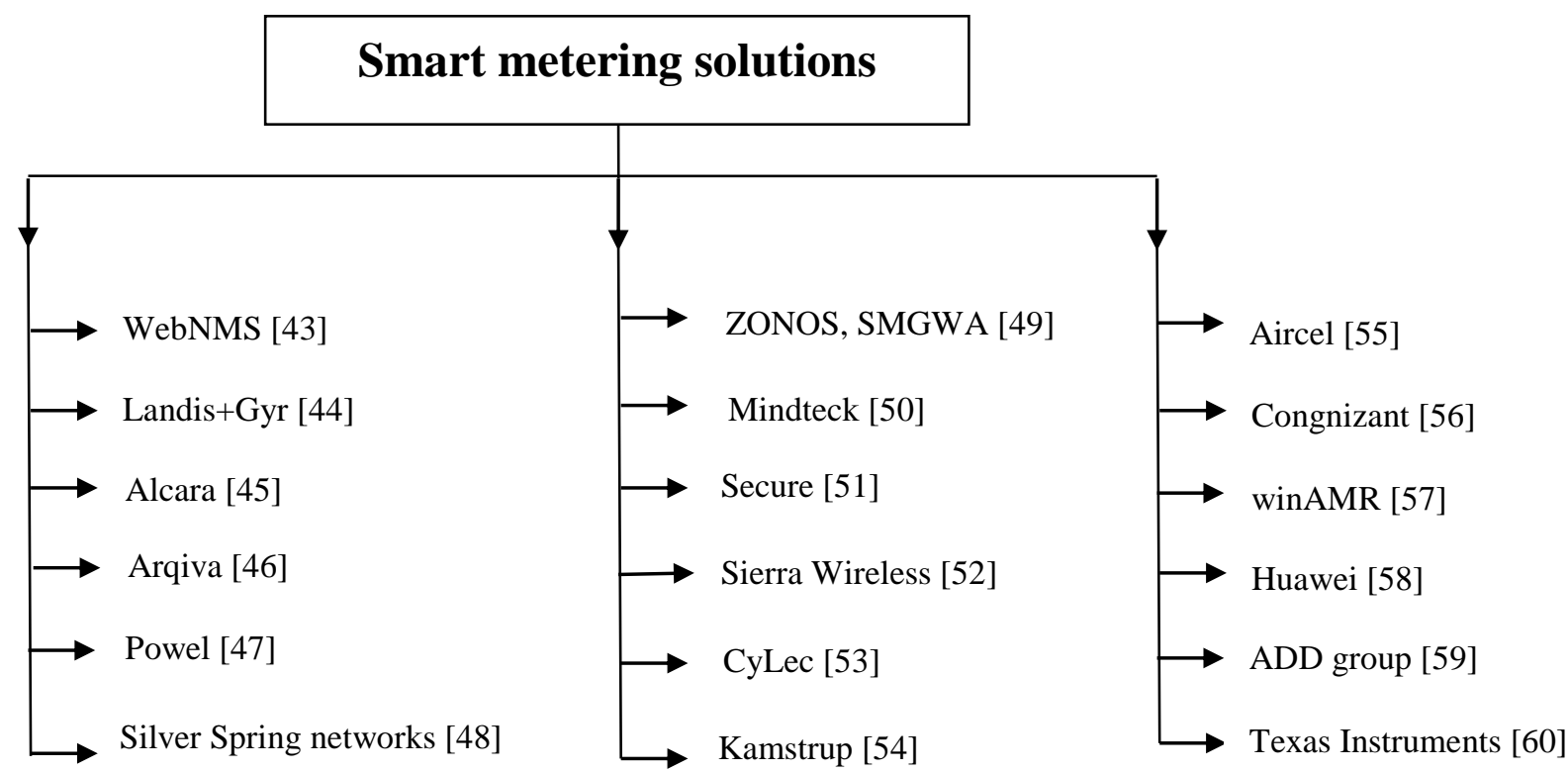

Figure 16. Represents Various Smart Metering Solutions Available in Market 
In most of the fields, the smart metering will make energy consumption more efficient in upcoming years. Smart metering devices make clear understanding to consumers and utilities about their real-time energy usage for better energy conservation. It will also facilitate the advancements in manufacturing, transportation, and wagons etc.

\section{Conclusion}

Smart meters in diverse corners of smart cities are not yet available everywhere in the world around. However, in many upgrading cities and utilities have been taken considerable initiatives and implementations. Energy infrastructure planners, builders, suppliers, operators and consumers are leading this movement. The evolving technology supports the vision into a reality. The SMs enable utilities (such as water system, transport system, intelligent home/building's demand response system, zero energy buildings, industry automation, renewable energy system, street lighting system, smart HVAC system, carbon management system, utilization of SMs in production of gas) to distantly turn service on and off at consumer premises. The numerous smart meters' deployment issues viz. Security, Big data management, Data integrity, Lack of regulatory policies, cost, RF exposure, accuracy are discussed in detail, those are required to be resolved for better deployment in future. Various smart metering solutions are enlisted, which give provision for better energy usage to consumers and utilities. Smart metering solutions are helpful for consumers those have to move out from their places and homes for service/work. Also, these cost-effective features eliminate the need to visit field for a utility. In future, remotely connecting feature will make possible for a utility to place consumers back into service more expeditiously. The technology supporting a smart city's buildings, infrastructure, industry and consumers continue to move towards more compatible, flexible, automated and intelligent platforms.

\section{Acknowledgement}

This work is supported by funding from Science and Engineering Research Board, New Delhi, India under File no. PDF/2016/001246.

\section{References}

[1] http://techcitynews.com/2016/06/15/smart-cities-will-need-smart-energy/.

[2] http://www.ict-smart-cities-center.com/en/smart-cities/energie/.

[3] https://www.bijlibachao.com/energy-efficiency-and-other-articles/what-are-smart-meters-smart-city-netsmartgrid-how-they-help-energy-management-efficiency-wattmeter.html.

[4] http://greencapacity.ru/information/smart-cities.

[5] A. Molina-Markham, P. Shenoy, K. Fu, E. Cecchet and D. Irwin, "Private Memoirs of a Smart Meter", in proceedings of BuildSys 2010, Zurich, Switzerland, (2010).

[6] P. Vijayapriya, G. Bapna and D.P. Kothari, "Smart Tariff for Smart Meters In Smart Grid", Journal of Engineering and Technology, vol.2, no.5, (2010), pp. 310-315.

[7] M.-J. Santofimia-Romero, X. del Toro-García and J.-C. López-López, "Artificial Intelligence Techniques for Smart Grid Applications", Green ICT: Trends and Challenges, Cepis Upgrade, vol. xii, no. 4, (2011), pp. 41-48.

[8] R. Kaushal, report submitted on "Challenges of Implementing Smart Grids in India", 14.01., (2011), pp. $1-10$,

[9] Y. Liu, "Wireless Sensor Network Applications in Smart Grid: Recent Trends and Challenges", International Journal of Distributed Sensor Networks, vol. 2012, article ID 492819, p. 8.

[10] M. Curiale, "From smart grids to smart city", in proceedings of Saudi Arabia Smart Grid Conference (SASG), Jeddah, (2014), pp. 1-9. 
[11] I. S. Jha, S. Sen and R. Kumar, "Smart Grid Development in India - A Case Study", in proceedings of Eighteenth National Power Systems Conference (NPSC), Guwahati, (2014), pp. 1-6.

[12] R. Kappagantu, "Smart grid implementation in India - A case study of Puducherry Pilot Project, India", 2015 International Conference on Energy Economics and Environment (ICEEE), Noida, (2015), pp. 2-27.

[13] S. P. Mohanty, U. Choppali and E. Kougianos, "Everything you wanted to know about smart cities: The Internet of things is the backbone", in IEEE Consumer Electronics Magazine, vol. 5, no. 3, (2016), pp. 60-70.

[14] http://cordis.europa.eu/news/rcn/126615_en.html.

[15] EU Skills Panorama, "Utilities and the introduction of smart grids and smart meters Analytical Highlight", prepared by ICF GHK and Cedefop for the European Commission, (2014).

[16] https://www.webnms.com/iot/smart-metering.html.

[17] Urban foresight report on, "Energy Systems and Electric Vehicles," prepared for: Transport Scotland, Victoria Quay, Edinburgh, Scotland, (2016).

[18] https://www.consumersenergy.com/uploadedFiles/smart-grid-diagram. pdf?n=6406

[19] R. Deng, Z. Yang, M. Y. Chow and J. Chen, "A Survey on Demand Response in Smart Grids: Mathematical Models and Approaches", in IEEE Transactions on Industrial Informatics, vol. 11, no. 3, (2015), pp. 570-582.

[20] L. Martiranoet, "Classification of smart metering systems for zero-energy buildings", in proceedings of IEEE 8th International Conference on Intelligent Data Acquisition and Advanced Computing Systems: Technology and Applications (IDAACS), Warsaw, (2015), pp. 68-74.

[21] https://thenewdystopia.files.wordpress.com/2015/07/2a8e518000000578-3162441-image-a-60_ 1436970861227.jpg.

[22] http://www.solarfeeds.com/net-zero-energy-a-realistic-expectation/net-zero-energy.

[23] "Automatic meter reading: Making utilities smarter and efficient", white paper by KPIT.com.

[24] http://energycite.com/patents.php.

[25] M.S. Hossaina, N.A. Madloolb, N.A. Rahima, J. Selvaraja, A.K. Pandeya and A. Faheem Khana, "Role of smart grid in renewable energy: An overview," Renewable and Sustainable Energy Reviews, vol. 60, (2016), pp. 1168-1184.

[26] http://m.c.lnkd.licdn.com/mpr/mpr/AAEAAQAAAAAAAAU2AAAAJGFmMTkxNjI2LWY4NGMtNG ViOC1hZDFkLWZmOWVkZDMyMjVmYQ.jpg.

[27] https://www.metering.com/street-lighting-problems-and-solutions.

[28] http://www.monitormymeter.com/images/street\%20light\%20solution.jpg.

[29] M. N. Sinha and R. W. Cox, "Improving HVAC system performance using smart meters", in proceedings of IEEE 2011 Energy Tech, Cleveland, OH, (2011), pp. 1-6.

[30] http://www.associatedrenewable.com/content/hvac-new-york.

[31] Darby SJ, McKenna E, "Social implications of residential demand response in cool temperate climates," Energy Policy, vol. 49, (2012), pp. 759-769.

[32] S. J. Darby, "The role of smart meters in carbon management", Carbon Management, vol. 4 no. 2, (2013), pp. 111-113.

[33] https://www.britishgas.co.uk/smarter-living/control-energy/smart-meters/what-are-smart-meters. html.

[34] http://www.mitie.com/services/energy-services/carboncare.

[35] https://www.wingas.com/en/raw-material-natural-gas/electricity-from-natural-gas.html.

[36] https://www.thebalance.com/smart-electric-meters-problems-1182585.

[37] H. Daki, A. El Hannani, A. Aqqal, A. Haidine and A. Dahbi, "Big Data management in smart grid: concepts, requirements and implementation", Journal of Bigdata, vol. 4, no. 13, (2017), pp. 1-19.

[38] L. Alejandro, C. Blair, L. Bloodgood, M. Khan, M. Lawless, D. Meehan, P. Schneider and K. Tsuji, "Global Market for Smart Electricity Meters: Government Policies Driving Strong Growth", U.S. International Trade Commission, (2014).

[39] L. Yang, X. Chen, J. Zhang and H. Vincent Poor, "Cost-Effective and Privacy-Preserving Energy Management for Smart Meters", IEEE Transactions on Smart Grid, vol. 6, issue: 1, (2015).

[40] "Health Impacts of Radio Frequency Exposure from Smart Meters", Final report submitted by The California Council on Science and Technology, (2011).

[41] https://www.iea.org/topics/electricity/futurescenariosforelectricity/.

[42] http://www.businessinsider.com/internet-of-things-utilities-water-electric-gas-2016-10?IR=T.

[43] https://www.webnms.com/iot/smart-metering.html.

[44] https://www.landisgyr.com.

[45] http://www.aclara.com/why-aclara/our-company/.

[46] https://www.arqiva.com/smart-metering/.

[47] https://www.powel.com/solutions/metering/.

[48] https://www.silverspringnet.com/solutions/metering-devices/.

[49] http://www.cuculus.net/en/Solutions/Smart-Metering.html.

[50] http://www.mindteck.com/wireless-and-iot-services-smart-energy-management-solutions.

[51] http://www.securemeters.com.

[52] https://www.sierrawireless.com/applications/energy-and-industrial/smart-metering/. 
[53] www.energetica-india.net/download.php?seccion=articles\&archivopdf.

[54] https://www.kamstrup.com/en-uk/news-and-events/news/kamstrup-adds-nb-iot-to-portfolio.

[55] http://www.aircel.com/AircelWar/appmanager/aircel/ABS?_nfpb=true\&_pageLabel=P10060034510145 5003549060.

[56] https://www.cognizant.com/energy-utility/smarter-utilities.

[57] http://www.winamr.com/.

[58] http://e.huawei.com/en/solutions/industries/smart-grid/consumption/ami.

[59] http://addgrup.com/products/classic-meters.

[60] http://www.mouser.com/new/texas-instruments/ti-smart-metering-solution/.

\section{Authors}

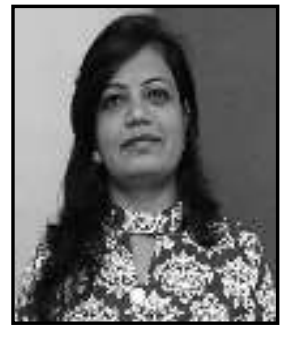

Kiran Ahuja, she has done outstanding research in the fields of optical and wireless communication. She received her B.Tech \& M.Tech degree in Electronics and Communication Engineering from Punjab Technical University, Jalandhar, India and Ph. D in Electronics \& Communication Engineering in wireless communication and networks field from Thapar University, Patiala, Punjab, India. She worked as faculty at DAVIET, Jalandhar since 2006. Presently, pursuing postdoctoral fellowship at NIT, Jalandhar under N-PDF scheme of SERB, India.

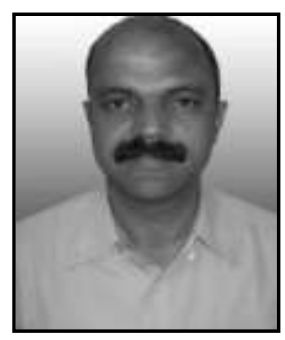

A. khosla, he was born in Punjab, India. He received the BE degree from Thapar University, India, M. Tech from NIT Kurukshetra, and Ph.D. degree from Kurukshetra University, India. His research areas include Artificial Intelligence, Bio Medical instrumentation. He is working as an Associate Prof. in the department of Electronics and Communication Engineering, NIT Jalandhar. 
International Journal of Grid and Distributed Computing

Vol. 11, No. 3 (2018) 